\title{
DETECTION OF VENOUS THROMBOSIS AMONG SUSPECTED VASCULAR LESIONS OF LOWER LIMBS BY DOPPLER SONOGRAPHY.
}

\author{
O. Guneshwar Singh, R. K. Jayshree Devi, Ksh. Achouba Singh.
}

1. Assistant Professor, Department of Orthopaedics, Jawaharlal Nehru Institute of Medical Sciences.

2. Assistant Professor, Department of Radiodiagnosis, Jawaharlal Nehru Institute of Medical Sciences.

3. Assistant Professor, Department of Endocrinology, Jawaharlal Nehru Institute Of Medical Sciences.

\section{CORRESPONDING AUTHOR:}

Dr. R. K. Jayshree Devi,

Nepra Menjor Mamang Leikai, Sagolband,

Imphal, Manipur.

E-mail: jaysdr80@yahoo.in

ABSTRACT: OBJECTIVE: To highlight the detection of venous thrombosis by doppler sonography in patients clinically suspicious of having vascular lesions in lower limb. MATERIALS AND METHODS: A total of 100 consecutive patients who were clinically suspicious of having vascular diseases of lower limb were subjected to doppler sonography. The study was carried out in the department of Orthopaedics \& Radiodiagnosis, J.N. Institute of Medical Sciences, Porompat, Imphal during the period between July, 2009 and December, 2012. RESULTS: The study includes 55 males and 45 females with the age ranging from 18-80years. Sonographic diagnosis was made in 80 patients and no abnormal findings were detected in 20 cases. The most common lesion detected was deep vein thrombosis (DVT) in 34(42.5\%) cases. The other lesions detected were $30(37.5 \%)$ cases of atherosclerosis, 15 (18.75) varicose vein, 5(6.35) synovial cysts, 3(3.8\%) superficial vein thrombosis (SVT), 2(2.5\%) each of aneurysm and arteritis, 1(1.3\%) each of arterial occlusive disease, arteriovenous malformation, acute lymph adenitis, calcified cystic lesions and inflammatory lesion. The commonest age group of DVT was between 41-50years and there was male preponderance with male: female (M: F) ratio of 1.26:1. The most commonly involved vein was posterior tibial vein (61.7\%). In $91.25 \%$, more than one vein was involved. The major associated risk factors for DVT were patients who had undergone major operations (38.9\%) and cancer patients (38.5\%). CONCLUSION: DVT and other vascular lesions of lower limb in clinically suspicious patients can be reliably diagnosed by Doppler sonography.

KEYWORDS: DVT (deep vein thrombosis), Doppler sonography, Duplex sonography, Colour Doppler.

INTRODUCTION: Venous thrombosis is an important complication seen after fractures of spine, pelvis, femur, tibia, etc. The pathogenesis has been described by Virchow's triad of venous stasis, vascular damage \& hypercoagulability. Some degree of venous thrombosis can be demonstrated in $24-86 \%$ of surgical patients, though incidence of symptomatic thrombosis is much lower. The exact figure on the incidence of DVT or pulmonary embolism in Indian population is not yet available. Nevertheless, between half and 3\% of the normal population suffer post-thrombotic symptoms. Fatal pulmonary embolism may occur suddenly in between one and two of every thousand hospital admissions ${ }^{1}$. Venous diseases can lead to various severe life threatening complications such as pulmonary embolism and systemic thromboembolism if not intervened in time. Post-operative deep vein thrombosis (DVT) can lead to pulmonary embolism in $60.0 \% 2$. The only accurate method of 
establishing or refuting the diagnosis of venous thrombosis is by venography, which is an invasive method. Doppler sonography which is non-invasive includes Duplex sonography, Colour doppler and Power doppler. Colour coded duplex sonography is the preferred method for diagnosis of venous diseases and is the gold standard as it gives the most comprehensive information for diagnosing functional disorders of the venous system ${ }^{3}$.

MATERIALS AND METHODS: The prospective study was carried out in the department of Orthopaedics and Radiodiagnosis, J.N. Institute of Medical Sciences, Porompat, Imphal during the period between July, 2009 and December, 2012 to highlight the detection of venous thrombosis by Doppler sonography in patients clinically suspicious of having vascular lesions in lower limb.

One-hundred consecutive patients clinically suspicious of having vascular lesions of lower limb were studied by performing Doppler sonography. Duplex Doppler, Colour Doppler and Power doppler were employed by using 7.5 MHz transducer (Toshiba Xario Colour Doppler machine). For better correlation the cases were broadly divided into seven groups based on clinical diagnosis and available relevant history as traumatic, post-operative, malignant, chronic bed ridden, cardiac, diabetic and nonspecific. The signs of venous thrombosis are (i) absent or reduced compressibility, (ii) thrombus in the vein (static echoes, incomplete colour fill-in, expansion of the vein), (iii) static valve leaflets, (iv) absent flow on spectral or colour Doppler, (v) impaired or absent augmentation of flow, (vi) loss of spontaneous flow and respiratory variation, (vii) increased flow in collateral channels.

Clinical scoring system was not done in the study as the aim of the study was to detect not only venous thrombosis but also different types of other venous lesions in lower limbs. Serum estimation of D-dimer which helps in reducing load on ultrasonography was also not done due to the following reasons: i) there were many post traumatic patients undergoing orthopaedic surgery ii) expected false positive result of the test in conditions like malignancy, infection etc. iii) inherent lack of specificity of the test.

RESULTS: In the study, sonographic findings in 100 cases were analyzed. The cases comprise of 55 males and 45 females with $\mathrm{M}$ : F ratio of 1.2:1. The age ranges from 18 to 80 years (Table 1).Maximum number of cases (17) was in the age group of 51-60 years and minimum (4) was in the age group of 11-20 years (Table 2). Out of the 80 cases in which positive lesions were detected, DVT was the commonest \& detected in $34(42.5 \%)$ cases. Out of 34 cases, 27 cases were of acute and 7 cases were of chronic DVT respectively. The other lesions detected were atherosclerosis in $30(37.55 \%)$ cases, varicose vein in $15(18.7 \%)$ cases, and synovial cyst in $5(6.3 \%)$ cases, 2 (2.5\%) cases each of aneurysm and arteritis, 1 (1.3\%) case each of arterial occlusive disease, A-V malformation, acute lymphadenitis, calcified cystic lesion and inflammatory lesion. In 20 patients no lesions were detected sonographically. The commonest age group for DVT was $41-50$ years (26.5\%) whereas it was 51-60 years (43.3\%) in atherosclerosis (Table $3 \mathbf{8 4}$ ).

In $11(32.4 \%)$ cases, DVT was associated with other vascular lesions. The associated lesions were $6(17.7 \%)$ cases of atherosclerosis, $4(11.8 \%)$ of varicose vein and $1(2.9 \%)$ SVT. DVT (55.9\%), atherosclerosis $(60.0 \%)$, varicosity $(86.7 \%)$ and SVT $(66.7 \%)$ were found to be more common in males. Two cases each of arteritis and aneurysm were found in females only and cases of synovial cysts were also found to be more common in females (Table 5). DVT was diagnosed in $7(38.9 \%)$ 
post-operative patients, $5(38.5 \%)$ cases of malignancies, $4(26.7 \%)$ cases of chronic bed ridden patients, $2(25.0 \%)$ cases of cardiac diseases and $3(23.1 \%)$ cases of diabetic patients. In $11(42.3 \%)$ cases, no specific clinical risk factors were detected (Table 6).

The veins involved in DVT were posterior tibial $(61.7 \%)$, popliteal $(47.1 \%)$, peroneal(44.1\%), superficial femoral(17.6\%), common femoral(11.7\%), anterior tibial(17.6\%) and external iliac(5.9\%). In $91.2 \%$ of the cases, more than one vein was involved.

DISCUSSION: In the study, sonographically diagnosable lesions were found in 80 patients but in 20 patients no abnormal findings were detected. DVT was the most common lesion with $34(42.5 \%)$ cases in which $27(33.7 \%)$ were acute and $7(8.7 \%)$ were chronic which is comparable with the finding of $42.3 \%$ acute DVT and $15.7 \%$ chronic DVT reported by Olowayeye OA etal ${ }^{4}$. However, in another study the most predominant lesion was in the superficial vein (42.5\%), DVT was observed in $21.0 \%$ only and in $21.1 \%$ findings were normal ${ }^{5}$.

There were altogether 52 venous lesions comprising of DVT (34), varicose vein (15) and SVT (3). Concomitant lesions of both deep and superficial veins observed in $8.2 \%$, which is lower than the reported figures of $14.9 \% 5$. In one-third of the SVT cases, there is associated asymptomatic DVT, similar association was reported in $24.0 \%{ }^{6}{ }^{6}$ The sonographic features observed in cases of acute DVT are venous dilatation with thrombus, non or partial compressibility and absence of doppler signal and features for chronic DVT are narrow thick wall vein, collaterals around vein and incompressibility. Similar features such as venous dilatation with thrombus, absence of doppler signal, frozen valves, thick wall vein etc. are also reported ${ }^{4}$.Male:Female ratio in the study is $1.26: 1$ which is comparable with the reports of Lee $\mathrm{C} \mathrm{H}$ et al having $\mathrm{M}: \mathrm{F}$ ratio of 1.5:17.

In $38.8 \%$ of the patients have had major operation in the recent past and $38.4 \%$ were cancer patients. The other important risk factors associated are chronic bed ridden patients (26.66\%) and those having history of heart diseases (25.0\%). However in 11 cases no specific risk factors were available. These findings can be compared with the reports of Beck RN et al and Zhu R et al8,9,10. In another similar study on patients with chronic disease and bedridden or with greatly limited mobility, the incidence of DVT was in $18.0 \%$, however all were asymptomatic ones ${ }^{10}$.

In the present study, patients who had trauma in the lower limbs had DVT in $28.6 \%$, however there are reports of much lower incidence $(12.9)^{11}$.The involved veins in the DVT are posterior tibial (61.7\%), popliteal vein (47.1\%), peroneal vein $(44.1 \%)$, superficial femoral vein $(17.6 \%)$, anterior tibial vein(17.6\%) and external iliac vein (5.9\%). In $91.2 \%$ of the cases more than one vein was involved and single vein involvement occurred in $8.8 \%$ which is higher than the reported figures of $5.3 \%{ }^{12}$.

Out of 52 venous lesions, varicosity was observed in $15(28.8 \%)$ cases and superficial venous thrombosis in $3(5.8 \%)$.There is a male preponderance $(86.7 \%)$ in the cases of varicosity. Majority (53.3\%) occur in the older people above 50years which is consistent with the findings of Chiesa $\mathrm{R}$ et al from Italy ${ }^{13}$.The other non-venous vascular lesions detected are $30(37.5 \%)$ cases of atherosclerosis, $2(2.5 \%)$ each of arteritis and aneurysm,1(1.3\%) case each of arterial occlusive disease and arterio-venous malformation. 8(10.0\%) cases of non-vascular lesions detected are $5(6.3 \%)$ cases of synovial cyst, $1(1.3 \%)$ each of acute lymphadenitis, inflammatory lesion and calcified cystic lesion. 
Compression mode ultrasound studies with doppler sonography have sensitivity of $95 \%$ and specificity of $96 \%$ for symptomatic proximal DVT. Specificity is in the range of $60-70 \%$ for isolated calf vein thrombosis. Iliac vein thrombosis is difficult to visualize during routine lower limb ultrasonographic study. Contrast venography/ MRI venography is indicated in such cases. Some of the pitfalls of ultrasound study are failing to place the probe perpendicular to skin, mistaking acute clot as chronic clot, technical difficulties in obese patients, patients with significant lower limb edema, scanning the vessel longitudinally, confusing lymph node, baker's cyst with DVT, difficulty in visualizing ilio femoral thrombosis. False positive result could be caused by weak signals due to obesity, excessive probe pressure distorting venous flow, interpretation of weak signals in the calf as thrombosis. False negative findings may be caused by thrombi isolated in the veins of calf, nonocclusive clot proximal to popliteal vein, incorrect interpretation by inexperienced personnel, acute thrombosis masked by changes of severe chronic disease, misinterpretation of increased saphenous flow in the presence of occluded superficial femoral vein etc.

MRI venography/ contrast venography is considered gold standard for detection of venous thrombosis but the disadvantage is high cost and its unavailability in many institutes. MRI has almost $100 \%$ sensitivity and specificity. Multislice CT may be done while doing CT of pelvis and upper leg but is not practical for assessment of all cases of possible DVT/ other venous lesion considering the radiation dose and the need for contrast injection.

CONCLUSION: Doppler sonography is a reliable method for the diagnosis of venous thrombosis as well as other vascular lesions. Clinically most of the vascular and non-vascular lesions can also mimic venous thrombosis in which doppler study can help in differentiating the lesions. In fact making a diagnosis of DVT requires both clinical assessment and objective testing because clinical features are non specific and investigations can be either false positive or false negative. Clinical diagnosis is also insensitive and non specific. Initial step in the diagnosis process is that the patients should be stratified into high, intermediate or low risk categories using validated clinical model. When the clinical probability is intermediate or high and venous ultra sound is positive, acute symptomatic DVT will be confirmed. When the probability is low and ultrasound is normal, DVT will be ruled out. Doppler sonography was chosen in our study as it is non invasive, highly sensitive, also useful in detecting other venous lesions of lower limb and easy availability of experienced personnel in our institute.

\section{REFERENCES:}

1. Barritt D W,Jordan S C. Anticoagulant drugs in the treatment of pulmonary embolism. A controlled trial. Lancet, 1960; 1: 1309.

2. Taniguchi S, Fukuda I, Daitoku K, Minakawa M, Odagiri S, Suzuki Y, Fukui K, Asano K, Ohkuma H. Prevalence of venous thromboembolism in neurosurgical patients. Heart Vessels, 2009 Nov; 24(6):425-428.

3. Tutta P, Phlébologue SGP, Melide. Anatomy by ultrasound of the veins in the leg. Essentials, Praxis (Bern 1994), 2006 May 17; 95(20): 815-820.

4. Olowoyeye OA, Awosanya GO, Soyebi KO. Niger. Duplex Ultrasonographic Findings in Patients with Suspected DVT. Postgrad Med Jr, 2010 June; 17(2):128-132. 
5. Vucaj-Cirilović V, Petrović K, Nikolić O, Til V, Nićiforović D, Hadnadev D. Klinickicentar Novi Sad. Duplex Doppler ultrasonography in the diagnosis of deep venous thrombosis of the lower extremities. Med Pregl, 2006 Jan-Feb; 59(1-2):11-14.

6. Binder B, Lackner HK, Salmhofer W, Kroemer S, Custovic J, Hofmann-Wellenhof R. Association between superficial vein thrombosis and deep vein thrombosis of the lower extremities. Arch Dermatol, 2009 Jul; 145(7):753-757.

7. Lee CH, Cheng CL, Lin L J, Tsai L M ,Yang YH. Epidemiology and predictors of short-term mortality in symptomatic venous thromboembolism. Circ Jr, 2011 July 25; 75 (8):19982004.

8. Beck-Razi N, Kuzmin A, Koren D, Sarig G, Brenner B, Haim N, Gaitini D. Asymptomatic deep vein thrombosis in advanced cancer patients; the value of venous sonography. J Clin Ultrasound, 2010 June; 38(5):232-237.

9. Zhu R, Wei S, Wu S, Gong H, Chen X. Early diagnosis of lower limb deep vein thrombosis after major orthopaedic surgeries. Zhongguo Xiu Fu Chong JianWaiKeZaZhi,2010 June; 24(6):730-734.

10. Arpaia G, Ambrogi F, Penza M, Ianes AB, Serras A, Boracchi P, Cimminiello C. Risk of venous thromboembolism in patients nursed at home or in long term care residential facilities. Int J Vasc Med, 2011:305-327.

11. Wang ZS, Wang HL, Chen CH, Jiao X, Ge XC, Deng HM. A multi-factorial correlation analysis of deep vein thrombosis after trauma to lower extremities. Zhonghua Yi XueZaZhi, 2009 Jun 2; 89(21):1472-1476.

12. Labropoulos N, Webb K M, Kang SS. Patterns and distribution of isolated calf deep vein thrombosis. J Vasc Surg, 1999; 30: 787-791.

13. Chiesa R, Marone EM, Limoni C, Volonte M, Petrini O. Chronic venous disorders. Correlation between visible signs, symptoms and presence of functional disease. J Vasc Surg, 2007; 46(2): 322-330.

Table 1: Sex distribution.

\begin{tabular}{|c|c|c|c|}
\hline Sex & $\begin{array}{c}\text { Lesions } \\
\text { (Nos.) }\end{array}$ & $\begin{array}{c}\text { Normal } \\
\text { cases (Nos.) }\end{array}$ & Total \\
\hline Male & 44 & 11 & 55 \\
\hline Female & 36 & 9 & 45 \\
\hline Total & 80 & 20 & 100 \\
\hline
\end{tabular}


Table 2. Age distribution.

\begin{tabular}{|c|c|c|c|}
\hline $\begin{array}{c}\text { Age groups } \\
\text { (years) }\end{array}$ & Male & Female & Total \\
\hline $11-20$ & 4 & 0 & 4 \\
\hline $21-30$ & 4 & 7 & 11 \\
\hline $31-40$ & 6 & 7 & 13 \\
\hline $41-50$ & 11 & 12 & 23 \\
\hline $51-60$ & 17 & 9 & 26 \\
\hline $61-70$ & 9 & 6 & 15 \\
\hline $71-80$ & 4 & 4 & 8 \\
\hline Total & 55 & 45 & 100 \\
\hline
\end{tabular}

Table 3. Age wise distribution of Venous lesions.

\begin{tabular}{|c|c|c|c|c|}
\hline $\begin{array}{c}\text { Age groups } \\
\text { (years) }\end{array}$ & $\begin{array}{c}\text { No. of } \\
\text { Patients }\end{array}$ & DVT & SVT & $\begin{array}{c}\text { Varicose } \\
\text { vein }\end{array}$ \\
\hline $11-20$ & 4 & $1(1)$ & - & 2 \\
\hline $21-30$ & 11 & 2 & - & 2 \\
\hline $31-40$ & 13 & $7(3)$ & 1 & 1 \\
\hline $41-50$ & 23 & 9 & 1 & 2 \\
\hline $51-60$ & 26 & $6(1)$ & 1 & 4 \\
\hline $61-70$ & 15 & $5(1)$ & - & 1 \\
\hline $71-80$ & 8 & $4(1)$ & - & 3 \\
\hline Total & 100 & $34(7)$ & 3 & 15 \\
\hline
\end{tabular}

DVT-Deep vein thrombosis, SVT-Superficial venous thrombosis

(Figures in the parenthesis indicate number of chronic DVT)

Table 4. Distribution of Arterial and Non vascular lesions.

\begin{tabular}{|c|c|c|c|c|}
\hline $\begin{array}{c}\text { Age groups } \\
\text { (years) }\end{array}$ & $\begin{array}{c}\text { No. of } \\
\text { Patients }\end{array}$ & ATHER & Others & $\begin{array}{c}\text { Non } \\
\text { Vascular }\end{array}$ \\
\hline $11-20$ & 4 & - & - & - \\
\hline $21-30$ & 11 & - & 1 (ANR) & $\begin{array}{c}1(\mathrm{LA}) \\
1(\mathrm{CCL})\end{array}$ \\
\hline $31-40$ & 13 & - & - & $1(\mathrm{INF})$ \\
\hline $41-50$ & 23 & 6 & $\begin{array}{c}1 \text { (ART) } \\
\text { (AOD) } \\
1(\mathrm{AVM})\end{array}$ & 1 (SC) \\
\hline $51-60$ & 26 & 13 & - & $2(\mathrm{SC})$ \\
\hline $61-70$ & 15 & 6 & $\begin{array}{c}1(\mathrm{ART}) \\
1(\mathrm{ANR})\end{array}$ & 2 (SC) \\
\hline $71-80$ & 8 & 5 & - & - \\
\hline Total & 100 & 30 & 6 & 8 \\
\hline
\end{tabular}


ATHER-Atherosclerosis, ANR-Aneurysm, ART- Arteritis AOD-Arterial occlusive disease, LA-Lymph adenitis AVM- Arterio-venous malformation, SC-Synovial cyst CCL-Calcified cystic lesion, INF-Inflammatory lesion

Table 5. Sex distribution of different lesions.

\begin{tabular}{|l|l|l|l|}
\hline Lesions & Male & Female & Total \\
\hline DVT & $19(55.9 \%)$ & $15(44.1 \%)$ & 34 \\
\hline ATHER & $18(60.0 \%)$ & $12(40.0 \%)$ & 30 \\
\hline $\begin{array}{l}\text { Varicose } \\
\text { vein }\end{array}$ & $13(86.7 \%)$ & $2(13.3 \%)$ & 15 \\
\hline $\begin{array}{l}\text { Synovial } \\
\text { cyst }\end{array}$ & $2(40.0 \%)$ & $3(60.0 \%)$ & 5 \\
\hline SVT & $2(66.7 \%)$ & $\mathrm{I}(33.3 \%)$ & 3 \\
\hline Arteritis & 0 & $2(100 \%)$ & 2 \\
\hline Aneurysm & 0 & $2(100 \%)$ & 2 \\
\hline $\begin{array}{l}\text { AV malfor- } \\
\text { mation }\end{array}$ & $1(100 \%)$ & 0 & 1 \\
\hline AOD & 0 & $1(100 \%)$ & 1 \\
\hline INF & 0 & $1(100 \%)$ & 1 \\
\hline LA & $1(100 \%)$ & 0 & 1 \\
\hline CCL & 0 & $1(100 \%)$ & 1 \\
\hline
\end{tabular}

DVT-Deep vein thrombosis, ATHER-Atherosclerosis

SVT-Superficial venous thrombosis, LA-Lymph adenitis AOD-Arterial occlusive disease, INF-Inflammatory lesion CCL-Calcified cystic lesion

Table 6. Risk group wise distribution of Venous thrombosis.

\begin{tabular}{|c|c|c|c|}
\hline Risk groups & $\begin{array}{c}\text { No. of } \\
\text { cases }\end{array}$ & DVT & SVT \\
\hline Traumatic & 7 & $2(28.6 \%)$ & - \\
\hline Post operative & 18 & $7(38.9 \%)$ & - \\
\hline Malignancies & 13 & $5(38.5 \%)$ & - \\
\hline $\begin{array}{c}\text { Chronic bed } \\
\text { ridden }\end{array}$ & 15 & $4(26.7 \%)$ & $2(13.3 \%)$ \\
\hline $\begin{array}{c}\text { Cardiac } \\
\text { disease }\end{array}$ & 8 & $2(25.5 \%)$ & - \\
\hline Diabetes & 13 & $3(23.1 \%)$ & - \\
\hline Non Specific & 26 & $11(42.3 \%)$ & $1(3.8 \%)$ \\
\hline Total & 100 & 34 & 3 \\
\hline
\end{tabular}

